\title{
REVISIÓN DE LA TRADUCCIÓN GRIEGA DE “LA LEYENDA DE TEFNUT” A PARTIR DE LA VERSIÓN DEMÓTICA I
}

\author{
REVISION OF THE GREEK TRANSLATION OF “THE LEGEND OF TEFNUT” IN DEMOTIC VERSION I
}

\author{
MARÍA PAZ LÓPEZ MARTÍNEZ \\ Universidad de Alicante
}

\begin{abstract}
Resumen. Volviendo al papiro griego del siglo III d.C. que recoge la leyenda de la diosa Tefnut y que abordamos ya en el número 23-24 de esta misma revista, establecemos ahora una comparación entre su contenido y el contenido de la versión egipcia original. Dicha comparación nos ha permitido dar cuenta del argumento y la estructura del papiro griego así como ordenar, con mayor seguridad, los 7 fragmentos de los que consta. Finalizamos concluyendo que la versión griega no es una traducción literal, sino una paráfrasis fiel a lo esencial del original egipcio e insistiendo, por último, en el interés del texto para un mejor conocimiento del origen de la narrativa de ficción griega.

Palabras clave. Diosa Tefnut, papiro griego, traducción, demótico
\end{abstract}

\begin{abstract}
Returning to the third-century AD Greek papyrus that recounts the Legend of the Goddess Tefnut, which we discussed in issues 23-24 of this journal, here we compare it with the original Egyptian version. This comparison enables us recognise the story line and structure of the Greek text and also put the 7 fragments of the papyrus into a more plausible order. We conclude that the Greek version is not a literal translation, but a faithful paraphrase of the substance of the Egyptian original and that this is a valuable text for gaining a better knowledge of the origin of Greek fiction.
\end{abstract}

Key words. Goddess Tefnut, Greek papyri, translation, Demotic

Recordemos que, en el número XXIII-XXIV de esta misma revista, nos ocupamos de la traducción al griego de una antigua leyenda egipcia conocida como el Mito del ojo del sol. Su argumento narra la huida de la diosa Tefnut al desierto de Nubia, lugar desde el que los dioses Tot y Shu han de traerla de vuelta a Egipto. Durante el viaje de regreso, Tot va contándole a Tefnut una serie de fábulas para mantenerla entretenida, por lo que el texto presenta la estructura de un relato principal en el que se van insertando una serie de historias, al estilo de las Mil y una noches. Como dijimos, el mito tiene, además, una importante carga simbólica, pues Tefnut es una diosa relacionada con la humedad, de manera que su vuelta a casa representa la inundación del río Nilo, elemento fundamental en la vida y el progreso del Antiguo Egipto'.

1. Para la conocer la bibliografía, así como el texto griego completo y su traducción, remitimos a López y Torallas 2004-2005, 185-195.
Ya vimos que el manuscrito que ofrece la versión más completa del mito es el papiro demótico de Leiden. De un total de 22 columnas que comprendería el relato completo, se han conservado 21 , pues la primera de ellas se ha perdido. Corresponde al año 100 d.C. y se han publicado dos ediciones magníficas del texto. Podemos calificar a cada una de ellas de "hija de su tiempo", tanto por sus múltiples aciertos como por sus contadas carencias. Spiegelberg publicó la primera en 1917, mientras que la más moderna es obra de Cenival y vio la luz en 1988. Ambas presentan la transcripción del texto, traducción al alemán y al francés, respectivamente, y el correspondiente comentario filológico palabra por palabra.

Con respecto a la bibliografía de la que disponemos sobre los otros testimonios en demótico, diremos que, en 1976, Tait publicó una edición muy completa de la columna mejor conservada del papiro de Oxford, mientras que Cenival hizo lo mismo con el papiro de Lille en 1985.

Refiriéndonos específicamente a la versión en griego, diré que la primera noticia que aparece 
publicada sobre este texto se recoge en el catálogo de papiros literarios del Museo Británico, publicado por Milne en 1927. Ya en esta breve mención, se ofrecen suplementos para algunas lagunas. Sin embargo, habrá que esperar hasta 1969 para ver publicada la editio princeps del texto completo por Stephanie West y hemos de decir que desde entonces el papiro ha recibido escasa atención.

Como quedó dicho, el papiro está fechado en el siglo III d.C. y lo componen siete fragmentos escritos en grafía uncial. Los caracteres son pequeños, pero regulares, muy cuidados y con pocos errores. Los fragmentos conforman 10 columnas, por lo menos; cada columna tendría unas 70 líneas, y cada línea unas 20/25 letras. El espacio entre las columnas mide un centímetro, aproximadamente. Estamos, por tanto, ante una copia de dimensiones algo mayores que las habituales. La edición de West de 1969 se elaboró cotejando el texto griego con el papiro de Leiden, a partir de los datos que ofrecía Spiegelberg, pues ésta era la única edición disponible entonces. En la actualidad, tenemos varias ediciones del texto demótico: además de la de Spiegelberg, la de Cenival de 1988, en el caso del papiro de Leiden, y las de Tait y de Cenival, para los fragmentos de Oxford y de Lille.

Entrando ya en el análisis del texto griego, diremos que el primer fragmento del papiro presenta los restos de dos columnas, parte del intercolumnio que hay entre ambas, y el margen inferior.

La primera columna recoge una de las conversaciones que mantienen Hermes y la diosa Tefnut, quien no aparece citada por su nombre en el propio texto, pero la podemos identificar con facilidad por la mención a su hermano Aresnufis, el dios Shu de la versión demótica. Si Hermes ya ha entrado en escena, quiere decir que no se trata del comienzo del relato.

Esto mismo ha sucedido en el rollo demótico que ha perdido, también, la primera columna donde, probablemente, se habría producido la discusión entre Tefnut y su padre, así como la retirada de la diosa al desierto. Igual que sucede en el texto demótico, en el papiro griego Tefnut y Hermes intercambian juramentos:

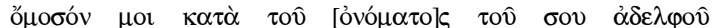

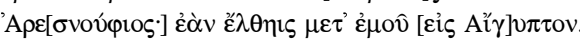

"júrame en nombre de tu hermano Aresnufis: Si vienes conmigo a Egipto..."

El dios hace todo lo posible por cumplir con la misión de traer de vuelta a Tefnut e intenta por todos los medios que le sea propicia. También encontramos estos detalles en el texto demótico:

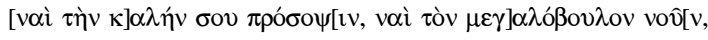

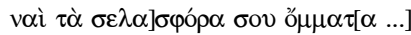

"Por tu bello rostro, por tu inteligencia de gran consejo, por tu mirada portadora de luz"

Por otro lado, constatamos que, en las dos narraciones, los protagonistas se metamorfosean en diferentes animales. En el papiro demótico, la diosa es llamada "la gata etíope", y Tot es "el pequeño mono cinocéfalo". En griego se utiliza el neologismo $\lambda v \kappa o ́ ~ \lambda \nu \gamma \xi$, que se suele traducir como "el chacal".

Con respecto a la segunda columna de este mismo fragmento, cabe decir que conserva buena parte de las 20 últimas líneas, que han perdido las letras finales. Por esta razón, las lagunas corresponden a una palabra o parte de una palabra, no más.

En este punto, Hermes vuelve a rogarle a la diosa que regrese a Egipto pronunciando un discurso que defiende el argumento de que todas las criaturas del mundo donde mejor viven es en la tierra que las vio nacer. El mismo tópico se explica, también con detalle, en el texto demótico. Sin embargo, el traductor griego no hace una traducción literal del pasaje, sino que se limita a plasmar la misma idea con sus propias palabras.

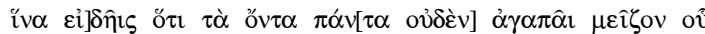

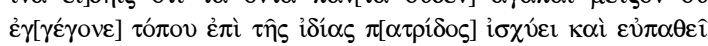

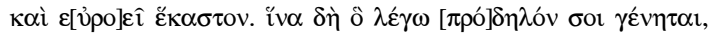

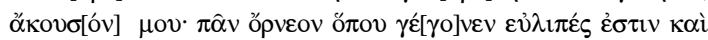

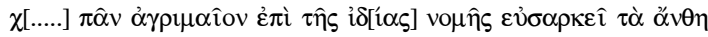

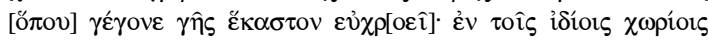

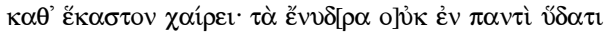

"Para que sepas que todos los seres nada aman más que el lugar donde han nacido. Cada uno, en su propia patria, es fuerte, feliz y florece. Para que quede claro lo que te digo, escúchame. Todos los pájaros están lustrosos donde han nacido; todos los animales salvajes están contentos en su propio pasto. Las flores tienen buen color en la tierra donde cada una ha nacido. Cada uno es feliz en su propia tierra. Los peces no se pasan la vida en cualquier agua,..."

El siguiente fragmento $B$ está muy mutilado. Es la parte central de una columna. Por el vocabulario, lo situamos hacia la mitad de la historia -en la columna número 12 del papiro demótico- cuando el pequeño mono cinocéfalo vuelve a pedirle, una vez más, a la gata etíope que regrese a Egipto y le anuncia que le va a contar una fábula.

A continuación, tenemos el fragmento $C$ que, como el anterior, también ha conservado el margen inferior y algo del final de la columna. Las letras que quedan pertenecen al centro de la línea. En opinión de West, es la misma columna que el fragmento anterior. La escena se sitúa en columna número 13 del papiro demótico, cuando la gata etíope se enfada y se metamorfosea en 
una leona de aspecto terrible. En el texto griego, Hermes se dirige asustado a Tefnut:

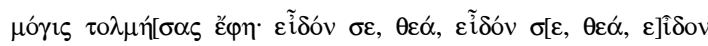

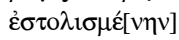

"Apenas atreviéndose le dijo: "te vi, diosa, te vi, diosa, te vi vestida"

El fragmento griego acaba con un adjetivo

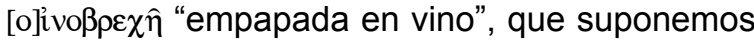
una aportación del traductor griego al relato. El texto griego no lo conserva, pero podemos conocer la continuación del episodio gracias al papiro demótico. El pequeño cinocéfalo vuelve a adular a la gata etíope, como ya ha hecho otras veces, y la diosa acaba recuperando el buen humor.

El fragmento $D$ es el que presenta mejor estado de todos los fragmentos que tenemos. Se recompuso como un puzle a partir de 3 pedazos que estaban separados. Conserva los restos de dos columnas de setenta líneas, los dos márgenes, el superior y el inferior, y el intercolumnio.

El contenido del fragmento es una serie de fábulas de animales que el pequeño cinocéfalo, también conocido por Kufi, le cuenta a la gata etíope para convencerla de que no lo mate.

Junto al papiro griego del Museo Británico y al papiro demótico de Leiden, tenemos un tercer testimonio de este pasaje del mito: se trata de otro papiro demótico que pertenece a los fondos del Ashmoleam Museum de Oxford. Es algo más antiguo que el de Holanda y fue publicado en 1976 por Tait, quien también reconoció el texto en la columna 14 del papiro de Leiden.

La primera fábula que aparece en la primera columna recoge la conversación que mantienen dos pájaros que son la Vista y el Oído. Por lo que respecta al texto griego, diremos que su estado es muy lagunoso. Posiblemente, el estudio detenido del papiro demótico aportará datos suficientes para proponer una reconstrución aproximada de las cincuenta primeras líneas de la columna.

A partir de la línea 50 a la 70, el estado del papiro griego es bastante bueno. Entre los temas que aparecen está el tópico de la ley del más fuerte, según la cual cualquier criatura es vencida por alguna otra que esté por encima de ella.

También se habla de la omniscencia de Zeus o Helios -nos podemos encontrar los dos nombres-. A su vez, el texto demótico recoge esta misma idea del vengador supremo que es el dios Ra.

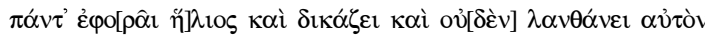

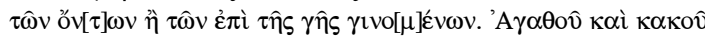

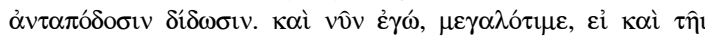

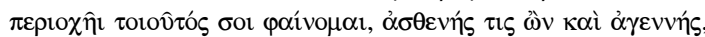

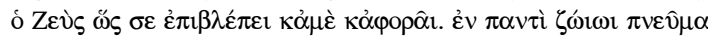

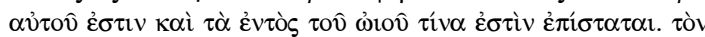

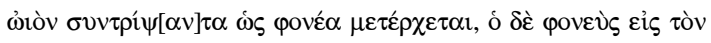

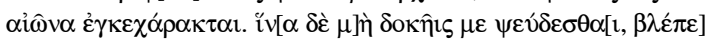

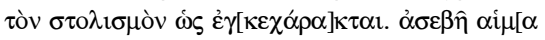

"Pues al Sol que todo lo contempla y lo juzga, no le pasa desapercibido nada de lo que existe o sucede en la tierra. Concede recompensa por el bien y por el mal. Y si yo ahora, ¡venerable señora!, también te parezco así por mi forma, siendo alguien débil y vulgar, Zeus, cuando te contempla a ti también me ve a mí. En todo ser vivo está su aliento y sabe lo que hay dentro del huevo. El huevo roto busca a su asesino, pero su asesino ha sido grabado para la eternidad y para que no creas que te engaño, mira el vestido cómo se ha grabado. Sangre impía ..."

La segunda columna de este mismo fragmento es la que mejor se conserva de todo el papiro. A pesar de ello, el texto es algo incoherente tanto en la versión griega, como en las dos versiones demóticas que tenemos, Leiden y Oxford. En las primeras líneas se sigue desarrollando el mismo tema que estábamos leyendo: la mancha de un asesinato no se limpia nunca, y para ello emplea la imagen de vestiduras manchadas con la sangre de un crimen que no se pueden lavar jamás.

Al llegar a este punto, se acaba el papiro de Oxford y volvemos a tener un solo testimonio demótico de este relato.

Desde la 20 a la 40, el texto está en muy malas condiciones. Abandona el tono misterioso y retoma la conversación entre ambos dioses. Hermes continúa pidiéndole a Tefnut que regrese a Egipto y acaba por arrancarle una sonrisa:

$\delta \varepsilon ́ \sigma \pi \mathrm{o}[\tau$,

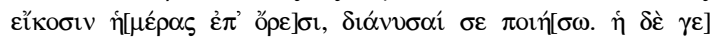
$\lambda \alpha ́ \sigma \alpha[\sigma \alpha \varepsilon \hat{i}] \pi \varepsilon$

"Señora, este es el camino que conduce a Egipto, si caminas por los montes durante veinte días, haré que lo termines".

A continuación, Hermes le cuenta otra fábula de dos chacales que se encuentran con un león. Éstos, al ver a la fiera, en lugar de salir huyendo, se detienen frente a él. El león extrañado por la reacción de los chacales les pregunta por qué no huyen a lo que ellos responden diciendo que prefieren ser devorados, mientras conservan todavía intactas sus fuerzas. El texto griego dice:

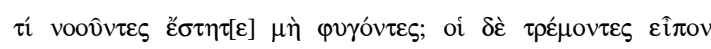

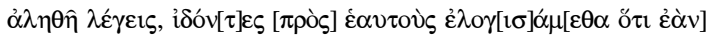
$v \dot{\gamma} \omega \mu \varepsilon v \kappa \alpha \tau \alpha \lambda \eta[\varphi \theta \eta \sigma o ́ \mu \varepsilon \theta \alpha]$

¿En qué estabais pensando cuando os levantasteis y no salisteis huyendo? Ellos le respondieron temblando: "Dices la verdad, mirando por nosotros, hemos pensado que, aunque huyéramos, íbamos a ser atrapados".

Así acaba el fragmento D. Los restantes ya son mucho más pequeños. El fragmento $E$ conserva el margen inferior y las últimas líneas de tres columnas muy mutiladas. Cuenta otra fábula en la que un león iba paseando por el desierto y se 
va encontrando con una serie de animales con señales de haber sido víctimas del maltrato. El león les pregunta quién ha sido quien les ha hecho daño y todos le dan la misma respuesta: "ha sido el hombre". Ante esto, el león les aconseja que tengan cuidado con el hombre, pues es una especie muy peligrosa:

Lo poco que queda de la tercera columna del fragmento $E$ no se identifica con ningún pasaje concreto del texto demótico. Son apenas un par de epítetos referidos a Helios, el Ra egipcio considerado la deidad suprema.

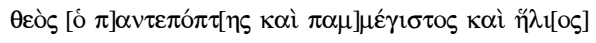

"El dios que todo lo ve, el más grande, Helios"

A continuación de este texto, habría que situar el papiro demótico de la Universidad de Lille. Está fechado en el año 200 d.C. Describe una procesión de portadoras de ofrendas y da cuenta del momento en el que, por fin, Tefnut toma la decisión de volver a Egipto. Según Cenival, el texto encaja en la columna número 19 del papiro de Leiden. Sin embargo, se trata de una versión diferente de este relato, pues los textos que presentan ambos manuscritos son distintos.

Por lo que respecta al fragmento F. Conserva el margen inferior, el intercolumnio y las últimas líneas de dos columnas, la primera de ellas muy mutilada. Narra la metamorfosis que experimentan los protagonistas del mito cuando llegan a la ciudad de Tebas: la gata etiópica se convierte en gacela y el chacal en lince. Probablemente, lo que sucedía en la leyenda era que la diosa cambiaba de aspecto a medida que atravesaba regiones diferentes, en su recorrido desde el desierto de Etiopía hasta Egipto. Episodio que el papiro de Leiden recoge casi al final, en la última columna del rollo.

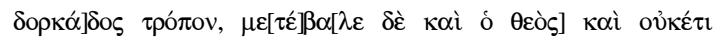

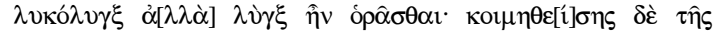

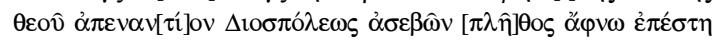

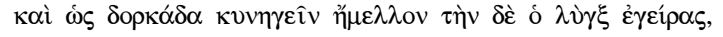

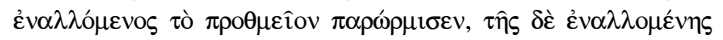

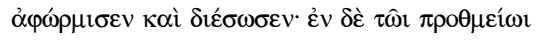

"Con la forma de una gacela, el dios también se transformó y ya no podía ser contemplado como un chacal, sino como un lince. Recostándose la diosa frente a Dióspolis, la muchedumbre de impíos se puso en pie de repente, también como si fuera a cazar una gacela...."
}

Con respecto al papiro griego, hemos de hacer constar que existe otro fragmento más que se conoce como Fragmento G. Su estado es tan malo que hasta ahora no se ha podido ubicar en la secuencia de fragmentos.

Por último, en la historia de Ojo del Sol, la hija de Helios acaba con el encuentro y posterior reconciliación del padre y su hija en Menfis, en medio de una gran fiesta.

Finalmente, diremos a modo de conclusión: En primer lugar, el cotejo del texto griego con el texto demótico (a través de las traducciones y comentarios a los que he tenido acceso) permite dar cuenta del argumento y de la estructura del relato. También es posible ordenar con bastante seguridad los 7 fragmentos de los que se compone el papiro griego.

En segundo lugar, constatamos que dicha traducción del demótico al griego no es una traducción literal, sino más bien una paráfrasis fiel al original, que recoge el sentido y la mayoría de los detalles del texto demótico.

Me gustaría hacer constar que West utilizaba en su edición del papiro griego el texto demótico a través de la edición y comentario de Spiegelberg. Por el contrario, ninguno de los editores modernos de los textos demóticos recogen una sola mención al texto griego. Como mucho constatan su existencia, reseñan la edición de West en la bibliografía, pero en el comentario lo ignoran completamente. Respecto al texto griego, sigue quedando mucho trabajo por hacer: revisar cuidadosamente las lecturas de West para las letras inciertas, así como los suplementos con los que completó muchas de las lagunas.

En cualquier caso, insistimos en la idea de que se trata de un testimonio importante para conocer la evolución de la literatura griega en la época helenística e imperial, por lo que continuaremos dedicándole nuestra atención en futuros estudios. Además, constituye uno de los pocos ejemplos en los que se ha conservado la traducción al griego de un relato egipcio, así como el propio texto egipcio original.

\author{
Profa. Dra. María Paz López Martínez \\ Área de Filología Griega \\ Dpto. Prehistoria, Arqueología, $\mathrm{H}^{\mathrm{a}}$ Antigua, \\ Filología Griega y Filología Latina \\ Universidad de Alicante \\ Apdo. Correos 99 \\ 03080 Alicante \\ maripaz.lopez@ua.es
}

\section{BIBLIOGRAFÍA}

LÓPEZ, M.P. y TORALLAS, S., 2004-2005: "La versión griega de la leyenda demótica del ojo del sol”, Lucentum, 2324, 185-195.

SPIEGELBERG, W., 1917: Der Ägyptische Mythus vom Sonnenauge. (Den Papyrus der Tierfabeln - "kufi") Nach dem Leidener Demotischen Papyrus I 384), Strassburg. 